Author has nothing to disclose with regard to commercial support.

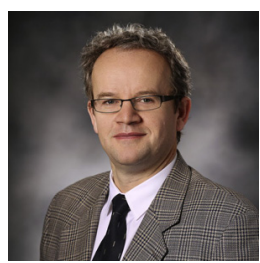

\section{SUBVALVULAR REPAIR TO IMPROVE REDUCTIVE ANNULOPLASTY FOR SEVERE MITRAL REGURGITATION Reply to the Editor:}

Mounting data underscore the shortcomings of isolated reductive annuloplasty for the repair of severe ischemic mitral regurgitation, and addition of a subvalvular repair, as elegantly introduced by Nappi and colleagues, ${ }^{1}$ may improve these suboptimal results. The evolution of these novel techniques will require progressive technical refinement, detailed imaging, and targeted patient selection. Image-guided lesion delineation should drive repair type and complexity on the basis of observed geometric annular and subvalvular perturbations, wall motion abnormalities, and regurgitant jet characteristics. Although an increasingly nihilistic attitude toward the technique of annular reduction is permeating the surgical community, a thoughtful approach to the annulus should not be discounted. These same investigators ${ }^{2}$ have demonstrated in a small randomized study that simple alteration of ring implantation technique may have a profound effect on ischemic mitral regurgitation recurrence at 12 months. None of the 18 patients treated with double-row implantation sutures in the study had more than mild mitral regurgitation develop during follow-up, which is well beyond the expectations of the Cardiothoracic Surgical Trials Network trial data. ${ }^{3}$ My group has similarly reported low 5-year recurrent ischemic mitral regurgitation rates in patients with severe left ventricular dysfunction with the etiology-specific GeoForm ring (Edwards Lifesciences Corp, Irvine, Calif), ${ }^{4}$ corroborating findings of other investigators. ${ }^{5}$ The complex etiology of ischemic mitral regurgitation is multifaceted and deserves to have attention focused on all of its components, both annular and subvalvular. A tailored reductive annuloplasty supplemented with a target-driven subvalvular repair holds the best promise of possibly achieving complete and durable repair for this challenging patient population. Facility with the growing customization of the surgical armamentarium will challenge the surgeon but surely benefit the patient.

Tomasz A. Timek, $M D, P h D$ Division of Cardiothoracic Surgery Spectrum Health Grand Rapids, Mich Michigan State University College of Human Medicine East Lansing, Mich

\section{References}

1. Nappi F, Spadaccio C, Nenna A, Lusini M, Fraldi M, Acar C, et al. Is subvalvular repair worthwhile in severe ischemic mitral regurgitation? Subanalysis of the Papillary Muscle Approximation trial. J Thorac Cardiovasc Surg. 2017;153: 286-95.e22.

2. Nappi F, Spadaccio C, Chello M, Lusini M, Acar C. Double row of overlapping sutures for downsizing annuloplasty decreases the risk of residual regurgitation in ischaemic mitral valve repair. Eur J Cardiothorac Surg. 2016;49:1182-7.

3. Acker MA, Parides MK, Perrault LP, Moskowitz AJ, Gelijns AC, Voisine P, et al; CTSN. Mitral-valve repair versus replacement for severe ischemic mitral regurgitation. N Engl J Med. 2014;370:23-32.

4. Timek TA, Hooker RL, Collingwood R, Davis AT, Alguire CT, Willekes CL, et al. Five-year real world outcomes of GeoForm ring implantation in patients with ischemic mitral regurgitation. J Thorac Cardiovasc Surg. 2014;148:1951-6.

5. De Bonis M, Taramasso M, Grimaldi A, Maisano F, Calabrese MC, Verzini A, et al. The GeoForm annuloplasty ring for the surgical treatment of functional mitral regurgitation in advanced dilated cardiomyopathy. Eur J Cardiothorac Surg. 2011;40:488-95.

http://dx.doi.org/10.1016/j.jtcvs.2017.05.076 